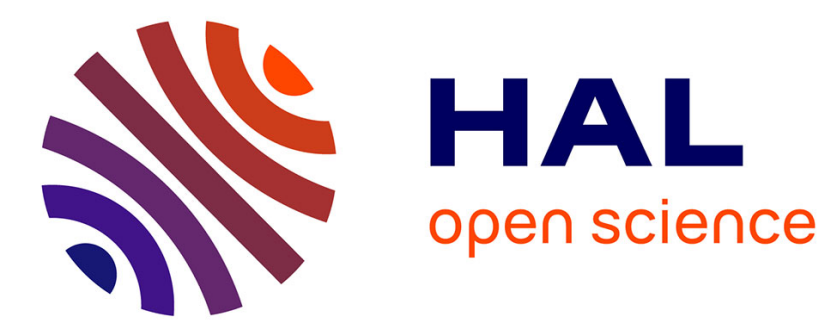

\title{
Variable compliance device for a respiratory physiotherapy training simulator
}

Tobias Bussing, Laurent Goujon, Christine Barthod

\section{To cite this version:}

Tobias Bussing, Laurent Goujon, Christine Barthod. Variable compliance device for a respiratory physiotherapy training simulator. Research and Education in Mechatronics, Nov 2012, Paris, France. pp. 199-204. hal-00870318

\section{HAL Id: hal-00870318 https://hal.science/hal-00870318}

Submitted on 7 Oct 2013

HAL is a multi-disciplinary open access archive for the deposit and dissemination of scientific research documents, whether they are published or not. The documents may come from teaching and research institutions in France or abroad, or from public or private research centers.
L'archive ouverte pluridisciplinaire HAL, est destinée au dépôt et à la diffusion de documents scientifiques de niveau recherche, publiés ou non, émanant des établissements d'enseignement et de recherche français ou étrangers, des laboratoires publics ou privés. 


\title{
Variable compliance device for a respiratory physiotherapy training simulator
}

\author{
Tobias Büssing, Laurent Goujon, Christine Barthod \\ SYstems and Materials for MEchatronics Laboratory (SYMME), \\ University of Savoie, BP80439, 74944 Annecy-le-Vieux, France \\ Email: Tobias.Bussing@univ-savoie.fr
}

\begin{abstract}
Semi active devices to modify the stiffness or the damping of systems received significant attention in the recent years. In this paper, two solutions of a variable compliance device to change the physiotherapists feeling of the thorax compliance of a 6-month old infant torso training simulator are presented. A first solution, using a variable orifice device which allows to change the compliance by changing the radius of a flow pipe is proposed. Another solution is to use a magnetorheological fluid damper. Both systems are presented in detail and discussed especially for their applicability to be integrated in the simulator.
\end{abstract}

\section{INTRODUCTION}

The paper deals with a variable parameter device based on semi-active modification systems. This device is supposed to be used for the realization of a simulator with variable characteristics for physiotherapists training. A simulator, designed to behave like an infant thorax, for respiratory physiotherapy gesture learning, has already been defined and realized [1]. The challenge is to be able to propose different clinical cases of infants of different ages and pathological situations. Therefore, this intended simulator should have the possibility to change some mechanical characteristics of the structure, particularly the compliance of the thorax felt by the practitioner. To find the required difference in compliance between the minimal and maximum cases, some tests with a referent physiotherapist were done and a factor around two was obtained [2].

As the physiotherapist gesture is a slow dynamic movement, this compliance variation can either be felt by a stiffness variation or by a damping variation [3]. A possibility for realizing such a device is to use piezoelectric dampers. These dampers consist, for example, of an elastic plate which is clamped along one side and equipped with some piezoelectric patches. By applying an adjusted electric current, the piezoelectric materials generate a significant amount of strain/stress to damp a force which acts on the free side of the plate [4]. But piezoelectric dampers are generally used for very small displacement amplitudes and thus they are not adapted to this application.

Another category of compliance modification devices are semi active stiffness dampers, which are widely used in semi active control devices [5]. Some of these systems are able to modify the damping force of a structure for a given displacement and therefore its global stiffness. Jabbari also presents a piston/cylinder system whose two chambers are

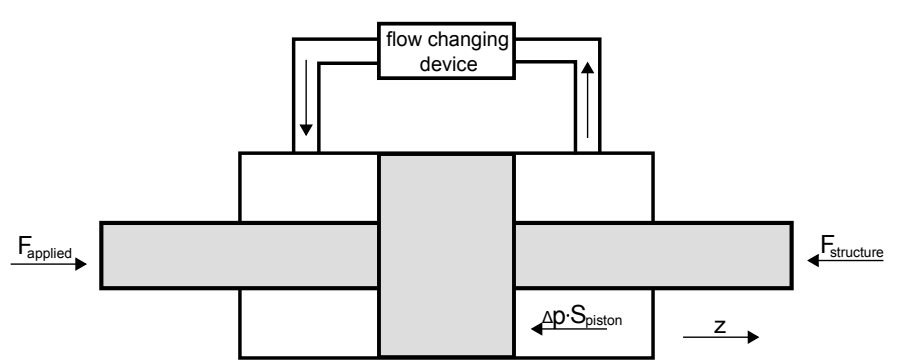

Figure 1. Cylinder/piston system with bypass

connected by a valve. This device works by adding stiffness to the system when the valve is closed, and dissipating the absorbed energy when the valve is opened [6].

A variant of the piston/cylinder system uses magnetorheological (MR) fluids. The damping force of this kind of device, as presented in [7], [8] for example, can be modified by varying the current in a coil that creates a magnetic field on the MR fluid.

Based on this device, a scheme of the solution, which is imagined to be implemented to modify the compliance felt by the physiotherapist on the training simulator, is indicated in fig. 1. It consists of two cylindrical chambers connected with a bypass with a flow changing device. The hydraulic fluid is forced through the bypass and crosses the flow changing device thanks to the movement of the piston. If the flow rate is decreased by the flow changing device, a higher force is necessary to obtain the same displacement of the piston for a given time, consequently the felt stiffness of the system increases.

This paper discusses and compares the two cylinder/piston variants supposed to be implemented for our study, a semiactive stiffness device and MR fluid device. Both solutions consist of a cylinder/ piston system with a bypass as a basic element to create the modification of the compliance. The first one uses a variable orifice and the second one a magnetorheological fluid. The two solutions for the flow changing device are presented and theoretically analyzed in section II and III respectively. In section IV the limits of the compliance modification are determined to analyze and discuss the feasibility of both cases. Furthermore the advantages and drawbacks of these two systems have been pointed out. 


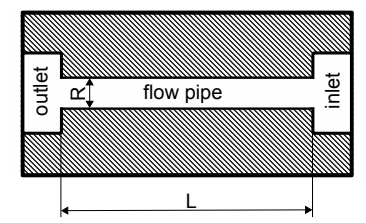

Figure 2. Schema of the flow changing device

\section{VARIABLE ORIFICE DEVICE}

\section{A. Description of the functioning}

The physical principle of this solution is relatively simple. The flow changing device acts as a valve. It consists of an inlet, an outlet and a flow pipe with an adjustable radius $\mathrm{R}$ (fig. 2). Changing the radius of the pipe modifies the flow. The modification of the radius can be done by a servo valve or by replacing the whole pipe. Due to this modification, the pressure drop between the two cylinder chambers is changing.

\section{B. Analytical analysis}

By application of the Navier Stokes equations, the pressure drop, as indicated in (1), is obtained [9].

$$
\Delta p=\frac{8 \cdot \mu \cdot L \cdot q}{\pi \cdot R^{4}}
$$

Where $\mu$ is the dynamic viscosity, $q$ is the flow rate, $L$ and $R$ are the length and the radius of the orifice respectively. Furthermore, the equilibrium of forces on the piston is given by

$$
m \cdot \ddot{z}=-\Delta p \cdot S_{\text {piston }}+F_{\text {applied }}-F_{\text {structure }}
$$

where $m$ is the mass of the piston (rod included), $S_{\text {piston }}$ is the piston area, $F_{\text {applied }}$ is the force which is applied by the physiotherapist and $F_{\text {structure }}$ is the force due to the stiffness of the structure. This force is determined by $F_{\text {structure }}=a \cdot z$ where $a$ is the stiffness of the simulator structure that has been previously determined $(\mathrm{a}=2860 \mathrm{~N} / \mathrm{m})$ [2].

By combining (1) and (2) and by replacing $q$ by $S_{\text {piston }} \cdot \dot{z}$, (3) is obtained.

$$
m \cdot \ddot{z}=-\frac{8 \cdot \mu \cdot L \cdot S_{\text {piston }}^{2}}{\pi \cdot R^{4}} \cdot \dot{z}+F_{\text {applied }}-F_{\text {structure }}
$$

As it is important that the system always behaves like a overdamped system, it was verified that the damping coefficient $\xi$, defined by (4), is always higher than 1 , for all the simulations described in this section.

$$
\xi=\frac{4 \cdot \mu \cdot L \cdot S_{\text {piston }}^{2}}{\pi \cdot R^{4} \cdot \sqrt{a \cdot m}}
$$

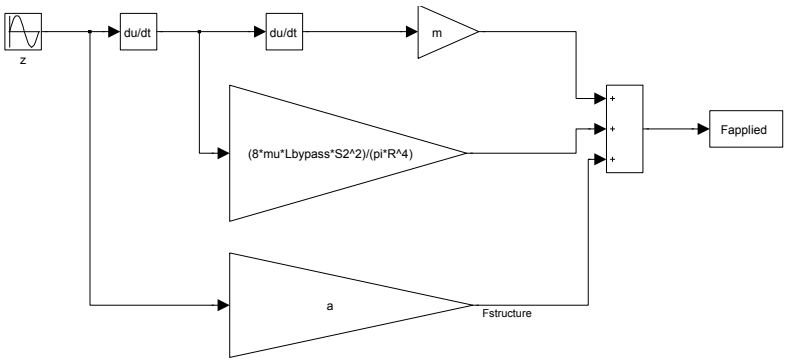

Figure 3. Simulation model of the variable radius orifice solution

\section{Simulation}

A Matlab-Simulink model (Fig. 3) was built to study the influence of different orifice lengths and different fluid viscosities as a function of the radius. The displacement of the thorax under the physiotherapist gesture, that has been characterized in [3], is supposed to be a half of a sinus with an amplitude of $16 \mathrm{~mm}$ and a frequency of $0.5 \mathrm{~Hz}$ (fig. 4). An example of the output signal $F_{\text {applied }}$ is depicted on the same graph. The orifice radius has been decreased from 3 to 1.5 $\mathrm{mm}$ and the maximum of $F_{\text {applied }}$ has been determined for each simulation.

The dimensions of the training simulator are those of a real 6 month old infant. Since the compliance modification system is supposed to be integrated inside the simulator, a cylinder/piston system with small dimensions is required. Hence, the CQSW B25 20 from SMC Corporation has been chosen. This choice determines some of the simulation parameters, in particular the piston mass $m=43.5 \mathrm{~g}$ and its area $S_{\text {piston }}=3.78 \mathrm{~cm}^{2}$.

\section{MagnetorheologiCAL FLUID DAMPER}

\section{A. Description of the functioning}

The second solution, which is discussed in this section, is a system based on a MR fluid. MR fluid is a smart material whose rheological properties can be changed fast and reversibly by applying a magnetic field. These fluids are nonmagnetic liquids such as oil or water with micronsized ferro-

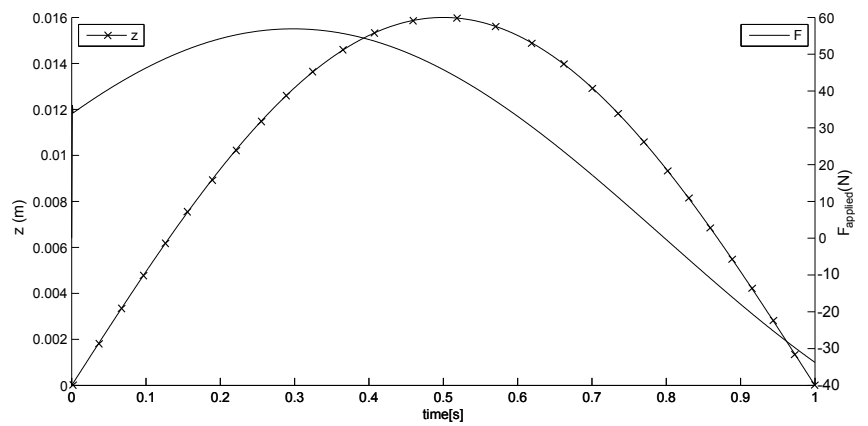

Figure 4. Input signal $\mathrm{z}$ and an example of the output signal $F_{\text {applied }}(\mathrm{L}=20$ $\mathrm{mm} ; \mathrm{R}=1.8 \mathrm{~mm} ; \mu=1 \mathrm{~Pa} \cdot \mathrm{s}$ ) 


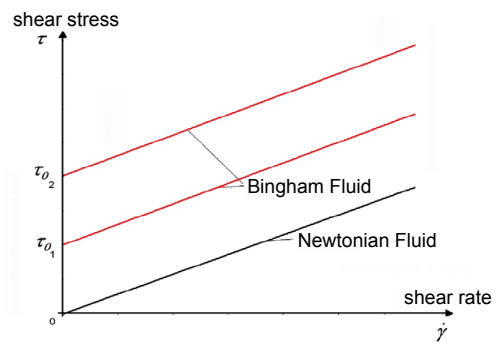

Figure 5. Shear stress vs. shear rate for Newtonian and Bingham model

magnetic particles which are forced by an external magnetic field to form a chain-like-structure [10]. A pole of one particle attracts the opposite pole of another particle. Due to the formation of these chains, the rheological status changes from a free-flowing state to a solid-like state. When no magnetic field is applied, the fluid behaves like a Newtonian fluid, but as soon as a magnetic field is applied, it behaves like a Bingham fluid. Before the fluid flow can occur, a threshold for the shear stress has to be reached. This threshold is the yield stress $\tau_{0}$ and depends on the magnetic field. Fig. 5 shows this shear stress as a function of the shear rate for Newtonian and Bingham fluids.

In this case, the main components of the flow changing device are a coil, a housing and a core. As shown in fig. 6, the fluid goes through a gap and the coil is wound around the core. The magnetic field, induced by the coupling of the coil and the core, is perpendicular to the direction of the fluid movement in the gap, allowing the control of the flow.

\section{B. Analytical analysis and simulation}

By application of the Navier Stokes equations for the above described solution, one obtains (5) which is recognized in the literature for describing the so-called valve mode (parallel plate model) [9]. A schematic of this mode is shown in fig. 7.

$$
\Delta p=\frac{12 \cdot \mu \cdot L \cdot q}{g^{3} \cdot w}+\frac{\operatorname{sgn}(\dot{z}) \cdot \tau_{0} \cdot L}{g}
$$

Where $\mu$ is the dynamic viscosity, $q$ is the flow rate, $\tau_{0}$ is the yield stress depending on the applied magnetic field, $L$,

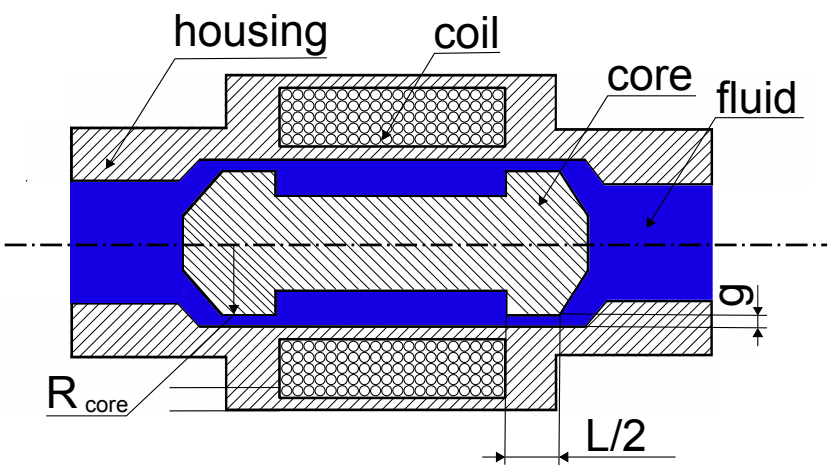

Figure 6. Flow changing device with magnetorheological fluid

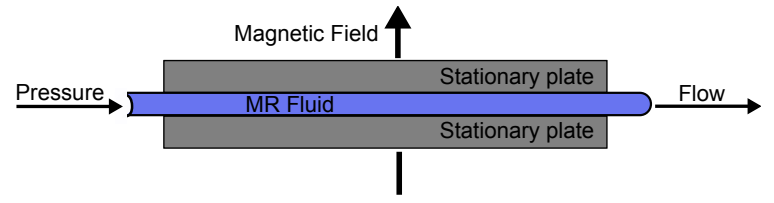

Figure 7. Schematic of valve mode

$w$ and $g$ are the length, width $\left(w=2 \pi R_{\text {core }}\right)$ and gap size of the flow channel respectively. The equilibrium of the forces on the piston is given by (2) as well.

By combining (5) and (2) and by replacing $q$ by $S_{\text {piston }} \cdot \dot{z}$, relation (6) is obtained:

$$
\begin{aligned}
m \cdot \ddot{z}= & -\frac{12 \cdot \mu \cdot L \cdot S_{\text {piston }}^{2}}{g^{3} \cdot w} \cdot \dot{z}-\frac{\operatorname{sgn}(\dot{z}) \cdot \tau_{0} \cdot L \cdot S_{\text {piston }}}{g} \\
& +F_{\text {applied }}-F_{\text {structure }}
\end{aligned}
$$

The parameters $\mathrm{m}$ and $S_{\text {piston }}$ are defined by the chosen piston/cylinder system and are the same as for the first solution. Furthermore, we also calculated the damping ratio $\xi$ in order to have an overdamped system (7).

$$
\xi=\frac{6 \cdot \mu \cdot L \cdot S_{\text {piston }}^{2}}{g^{3} \cdot w \cdot \sqrt{a \cdot m}}
$$

Fig. 8 shows the behavior of $\xi$ as a function of $\mathrm{L}$ and $\mathrm{g}$ for a dynamic viscosity of $\mu=0.24 \mathrm{~Pa} \cdot s$ (typical value of commercialized fluids of BASF [11] and Lord Corporation [12]). Several combinations of length and gap size are possible to ensure a damping ratio above one. We choose $\mathrm{L}=12$ $\mathrm{mm}$ and $\mathrm{g}=1.2 \mathrm{~mm}$ which give a value of $\xi=1.8$. This value leads to a system that should not be too overdamped.

The first two terms of (6) which are depending on the geometric of the cylinder/piston system, are defined as

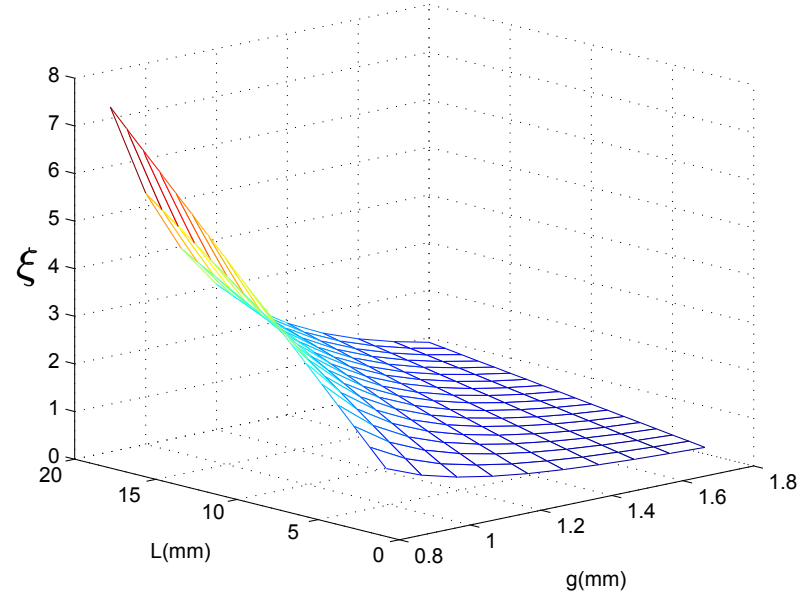

Figure 8. Damping ration $\xi$ as a function of $\mathrm{L}$ and $\mathrm{g}(\mu=0.24 \mathrm{~Pa} \cdot s)$ 


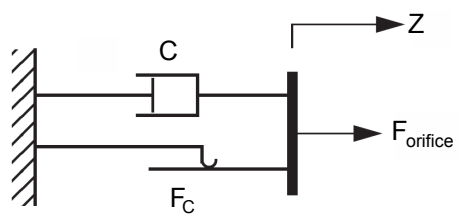

Figure 9. Schematic of the Bingham model

$F_{\text {orifice. }}$. Furthermore a damping coefficient $c$ and a friction force $F_{c}$ are defined, thanks to these terms:

$$
\begin{aligned}
F_{\text {orifice }} & =-\frac{12 \cdot \mu \cdot L \cdot S_{\text {piston }}^{2}}{g^{3} \cdot w} \cdot \dot{z}-\frac{\operatorname{sgn}(\dot{z}) \cdot \tau_{0} \cdot L \cdot S_{\text {piston }}}{g} \\
& =c \cdot \dot{z}+F_{c} \cdot \operatorname{sgn}(\dot{z})
\end{aligned}
$$

The phenomenological model, presented in (8), is known as the Bingham model. It consists of a Coulomb friction element and a viscous damper. A schematic of the model is shown in fig. 9.

In fig. 10 the Matlab-Simulink model is depicted. A sinusoidal period with an amplitude of $16 \mathrm{~mm}$ and a frequency of $0.5 \mathrm{~Hz}$ has also been used as input displacement. The force developed at the orifice as a function of the fluid velocity is shown in fig. 11. The shape is typical of the Bingham model and beyond the yield point, corresponding to the force $F_{c}$, a fully fluid flow occurs with a viscosity equal to c. Nevertheless, small deformations in the pre- and postyield regions are not considered by the Bingham model. In order to account for these deformations, a hysteretic model has been used.

The so-called Bouc-Wen model [13] is a phenomenological model which has been used extensively for modeling hysteretic systems. A schematic of this model is shown in fig. 12.

The orifice force for the Bouc-Wen model is described by:

$$
F_{\text {orifice }}=c \cdot \dot{z}+\alpha \cdot x
$$

where the evolutionary variable $\mathrm{x}$ is governed by:

$$
\dot{x}=-\gamma \cdot|\dot{z}| \cdot x \cdot|x|^{n-1}-\beta \cdot \dot{z} \cdot|x|^{n}+A \cdot \dot{z} .
$$

The Matlab Simulink model of the Bouc-Wen model is shown in fig. 13. The parameters $c, \alpha, \beta, \gamma, n$ and $A$

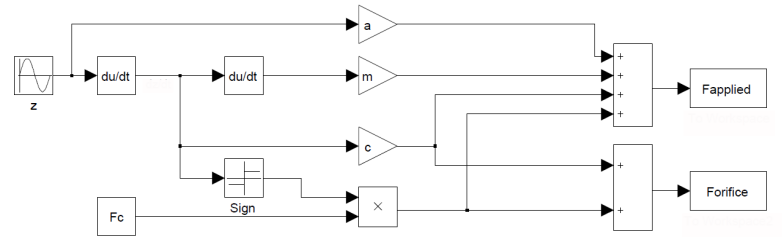

Figure 10. Matlab-Simulink model of the flow changing device using the Bingham model

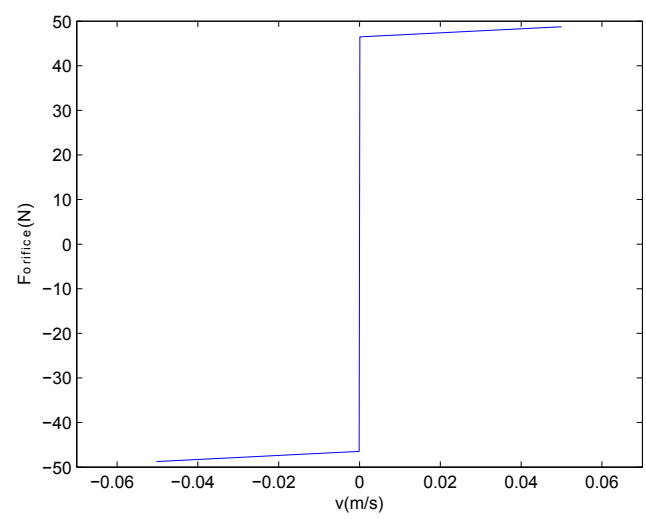

Figure 11. Orifice force vs. Velocity for the Bingham model $\mathrm{L}=12 \mathrm{~mm}$; $\mathrm{g}=1.2 \mathrm{~mm}$

are called shape or characteristic parameters of the BoucWen model. The parameter $\mathrm{c}$ is determined by (3) and (9). Unfortunately, there is no analytical method to determine $\alpha, \beta, \gamma, n$ and $A$. In the literature they are mostly estimated by trial and error techniques using experimental data obtained with a prototype [14]. The parameters $\beta, \gamma, n$ and $A$ determine the shape of the hysteresis. In this study the values determined by Spencer are used $\left(\beta=10^{6} \mathrm{~m}^{-2}, \gamma=10^{6}\right.$ $m^{-2}, n=2, A=120$ ) [15]. Nevertheless, the parameter $\alpha$ defines the amplitude of the force. To determine this parameter, the Bingham model was used. This model uses only physical parameters like the viscosity and the yield stress, which are known. As shown in fig. 14, the yield stress $\tau_{0}$ and the characteristic parameter $\alpha$ are chosen in order that the two models show the same behavior in the fluid state, for velocity values higher than $0.01 \mathrm{~m} / \mathrm{s}$. By using this method, a ratio of around 0.5 between $\alpha$ and $\tau_{0}$ is found.

By using (11), the required force $F_{\text {applied }}$, which has to be applied to achieve the desired displacement of $16 \mathrm{~mm}$, can be calculated.

$$
F_{\text {applied }}=m \cdot \ddot{z}+c \cdot \dot{z}-\alpha \cdot x+F_{\text {structure }}
$$

In fig. 15, examples of applied force for the Bingham and Bouc-Wen models as well as the input displacement signal $z$ are depicted. In this figure, one can see a drop of the force,

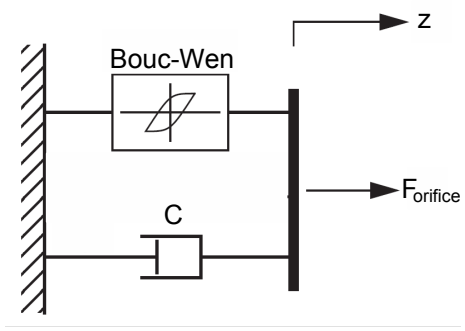

Figure 12. Schematic of the Bouc-Wen model 


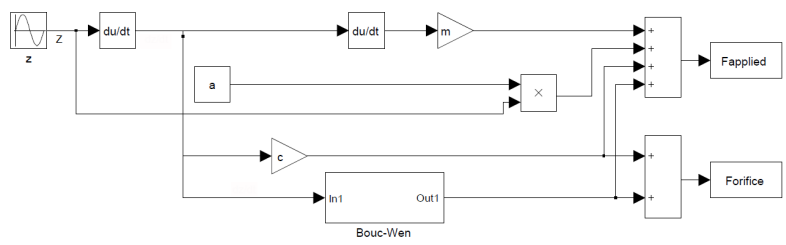

(a) Entire model

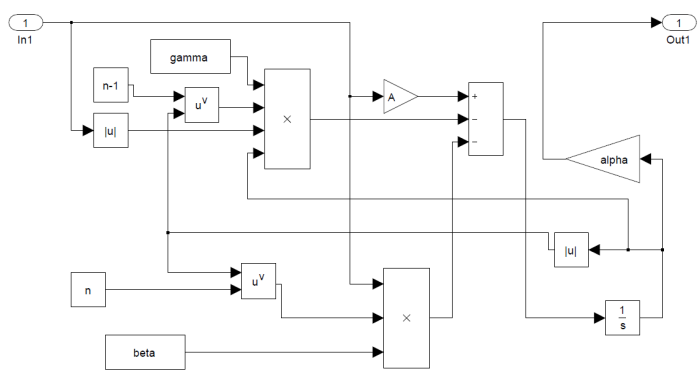

(b) Subsystem of the Bouc-Wen part

Figure 13. Matlab-Simulink model of the flow changing device using the Bouc-Wen model

when the maximum displacement is achieved and the velocity is very low. This drop, which is caused by the discontinuity in the models, is smoother for the Bouc-Wen model due to the hysteretic behavior. It should be noted the maximum values of the two models are identical.

\section{RESUlTS AND DiscUSSION}

\section{A. Variable orifice device}

The system to modify the compliance of the thorax should be integrated in the simulator. Hence, there is a very important size limit constraint. Due to this constraint, only an orifice length until $40 \mathrm{~mm}$ is possible to integrate. Therefore the behavior of the required forces to achieve the given displacement for orifice lengths of 40, 20,10,5 or $1 \mathrm{~mm}$ is studied as a function of the radius. As explained in section II-C, the maximum value of the applied force has been determined for

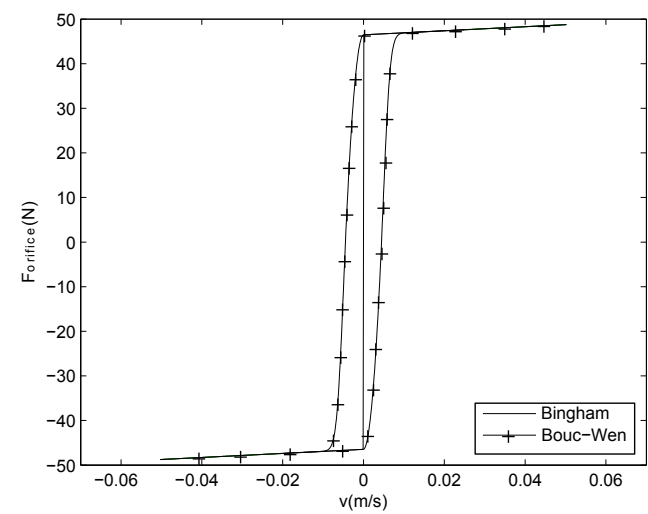

Figure 14. $F_{\text {orifice }}$ vs. Velocity for Bingham and Bouc-Wen models

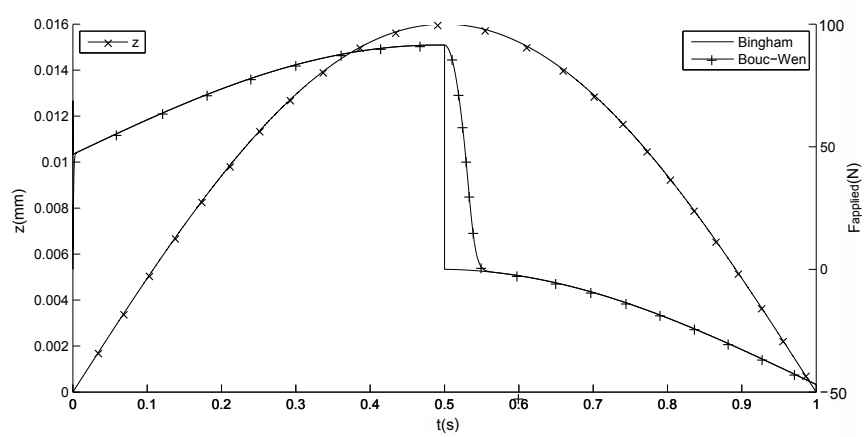

Figure 15. Input signal $\mathrm{z}$ and examples of the output signal for the Bingham and Bouc-Wen models $\left(\tau_{0}=12300 \mathrm{~Pa}\right.$ and $\left.\mu=0.24 \mathrm{~Pa} \cdot \mathrm{s}\right)$

each radius value (Fig. 4). The results are depicted in fig. 16.

The analysis of fig. 16 shows that for the five simulated lengths, no force change is observed for an orifice radius of $2.5 \mathrm{~mm}$ or higher. Thus for these radii, the influence of the valve is insignificant. As expected, by reducing the orifice radius, the required force increases. It is also observed that a factor of two can be obtained on the applied force and therefore on the compliance. But the shorter the orifice length is, the smaller the radius of the orifice has to be to obtain this required factor. However for an orifice length of $1 \mathrm{~mm}$, the slope is very steep. Thus, to change the value of the required force, the modification of the orifice radius must be very accurate. Hence, a variable compliance system based on a variable orifice device, with an orifice length of $5 \mathrm{~mm}$ seems to be the best compromise between fabrication issues and saving of space in the simulator. Furthermore the effect of different values of the fluid viscosity has been analyzed. Damping oils with a dynamic viscosity from 0.2 to $1 \mathrm{~Pa} \cdot s$ are routinely available. In fig. 17, simulations of the required force as a function of the orifice radius, for an orifice length of $5 \mathrm{~mm}$,

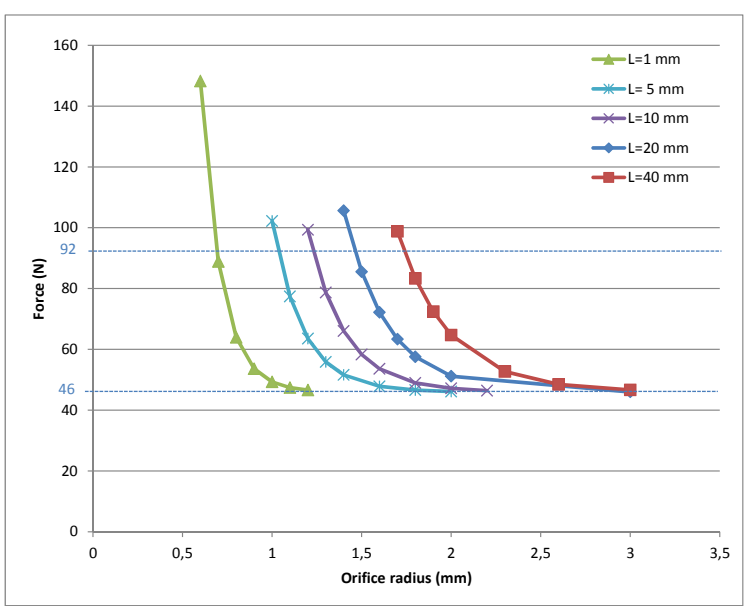

Figure 16. Required force as a function of the radius for different orifice lengths for $\mu=1 P a \cdot s$ 


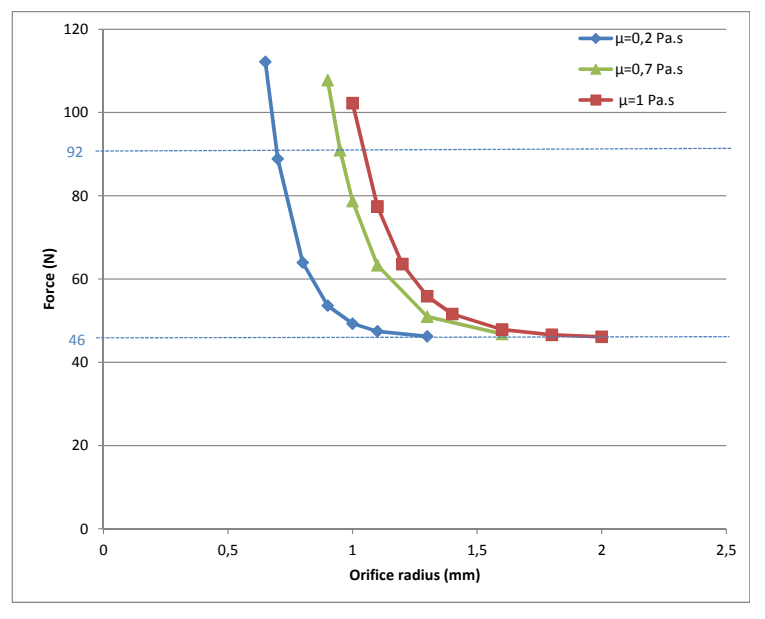

Figure 17. Required force as a function of the radius for different values of the viscosity $(\mathrm{L}=5 \mathrm{~mm})$

are depicted for different viscosity values. These simulations show that the increase of the viscosity induces a shift of the curves towards a higher radius. Moreover fig. 16 shows that higher radii lead to choose shorter orifice lengths to obtain the required force effect. Hence, a fluid with a high viscosity value should be preferred to design a more compact device.

The simulations have shown that the required modification of the compliance felt by the physiotherapist can be achieved with a variable orifice device. The limited size of this device implies an orifice radius that would be able to vary between $1 \mathrm{~mm}$ and $1.5 \mathrm{~mm}$ for a viscosity equal to $1 \mathrm{~Pa} \cdot \mathrm{s}$.

\section{B. Magnetorheological fluid damper}

Fig. 18 represents the evolution of the applied force as a function of the yield stress of the MR fluid. This figure enables one to observe that the required factor of two on the force can be achieved for a yield stress value of $12300 \mathrm{~Pa}$, which is realistic in practice [11]. On the one hand, this solution is more complex than the first solution, as it requires more equipment like an electromagnet and its electric source, but on the other hand, it allows changes of the compliance in a very elegant way, just by changing the current of the electromagnet.

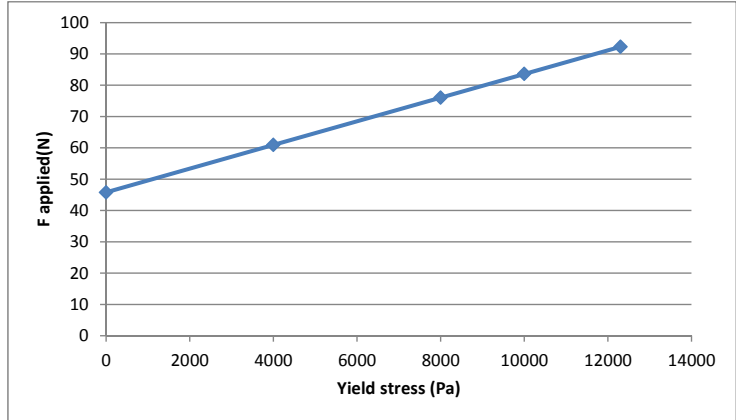

Figure 18. Force vs. yield stress $(\mathrm{L}=12 \mathrm{~mm}, \mathrm{~g}=1,2 \mathrm{~mm})$

\section{CONCLUSION AND OUTLOOK}

Two solutions of a variable compliance device to change the physiotherapists feeling of the simulator compliance have been discussed in this paper. The variable orifice damper and the magnetorheological fluid damper have been introduced and described. Analytical analyses have been shown, and simulations to show the feasibility of the methods have been run.

The dimensions of the variable orifice damper have been calculated in order to achieve the desired amount of compliance modification.

The characteristics of a system using a MR fluid have also been determined, as well as the required yield stress to make sufficient change in the compliance. However, further calculations are needed to dimension the electromagnet and completely assess the feasibility of this solution in the context of the simulator. In a further step, a prototype of each solution has to be realized to verify the simulation results.

\section{REFERENCES}

[1] L. Maréchal, C. Barthod, L. Goujon, and T. Büssing, "Design and development of a mechatronic infant torso simulator for respiratory physiotherapy learning," Mechatronics, vol. 22, no. 1, pp. 55-64, Feb. 2012.

[2] T. Büssing, "Required compliance range for an infant thorso physiotherapy training simulator," internal report, unpublished.

[3] L. Maréchal, C. Barthod, and J. C. Jeulin, "First characterization of the expiratory flow increase technique: method development and results analysis." Physiological measurement, vol. 30, no. 12, pp. 1445-64, Dec. 2009.

[4] G. Caruso, S. Galeani, and L. Menini, "Active Vibration Control of an Elastic Plate Using Multiple Piezoelectric Sensors and Actuators," Simulation Modelling Practice and Theory, vol. 11, no. 5-6, pp. 403-419, Aug. 2003.

[5] N. R. Fisco and H. Adelii, "Smart structures: Part I - Active and semi-active control," Scientia Iranica, vol. 18, no. 3, pp. 275-284, Jun. 2011.

[6] F. Jabbari and J. E. Bobrow, "Vibration Suppression with Resettable Device," Journal of Engineering Mechanics, no. September 2002, pp. 916-924, 2003.

[7] A. G. Olabi and A. Grunwald, "Design and application of magnetorheological fluid," Materials \& Design, vol. 28, no. 10, pp. 2658-2664, 2007.

[8] A. Milecki and M. Hauke, "Application of magnetorheological fluid in industrial shock absorbers," Mechanical Systems and Signal Processing, pp. 1-14, Dec. 2011.

[9] A. Grunwald and A. Olabi, "Design of magneto-rheological (MR) valve," Sensors and Actuators A: Physical, vol. 148, no. 1, pp. 211-223, Nov. 2008.

[10] M. Jolly, J. Bender, and J. Carlson, "Properties and applications of commercial magnetorheological fluids," Journal of Intelligent Material Systems and Structures, vol. 10, no. 1, p. 5, 1999.

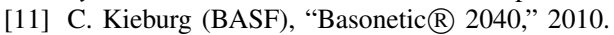

[12] L. Corporation, "MRF-140CG Magneto-Rheological Fluid," 2008.

[13] Y. Wen, "Method for random vibration of hysteretic systems," Journal of the Engineering Mechanics Division, vol. 102, pp. 249-263, 1976.

[14] A. Dominguez, R. Sedaghati, and I. Stiharu, "A new dynamic hysteresis model for magnetorheological dampers," Smart Materials and Structures, vol. 15, no. 5, pp. 1179-1189, Oct. 2006.

[15] B. Spencer, S. Dyke, M. Sain, and J. Carlson, "Phenomenological model for magnetorheological dampers," Journal of engineering mechanics, vol. 123, no. 3, pp. 230-238, 1997. 